\title{
Mundo da vida e educação: racionalidade e normatividade
}

Professor da Universidade de Passo Fundo, RS

\section{Resumo}

Habermas começa a atribuir, a partir de 1990, um papel fundamental ao mundo da vida, passando a considerá-lo como fonte da racionalidade comunicativa, capaz de se opor ao processo de dominação sistêmica e manter a autonomia dos indivíduos pelo entendimento. Este texto procura explicitar os argumentos que levam Habermas a considerar a espontaneidade geradora do mundo da vida como fonte que assegura a validade cognitiva e normativa das ações dos indivíduos em interação e avaliar o potencial crítico desse posicionamento no campo educacional. A hipótese orientadora sustenta-se na ideia de que o efetivo entendimento da vida cotidiana escolar só pode ser atingido se levarmos em conta a forma de produção e reprodução do mundo da vida dos atores que o compõem.

Palavras-chave: Mundo da vida; Racionalidade; Habermas.

\begin{abstract}
Since 1990 Habermas began assigning a key role to lifeworld, considering it as the source of communicative rationality, one that is able to oppose the process of systemic domination and sustain the autonomy of individuals through understanding. This paper is aimed at explain the arguments that have led Habermas to consider the spontaneity that generates lifeworld as the source that ensures the normative and cognitive validity of the actions of individuals in interaction and assess the critical potential of such position in the educational field. The guiding hypothesis is grounded on the assumption that the effective understanding of everyday school life can only be achieved if one takes into account the means of production and reproduction of the lifeworld of the actors that constitute it.
\end{abstract}

Keywords: Lifeworld; Rationality; Habermas.

Filosofia e Educação [RFE] - Volume 8, Número 2 - Campinas, SP Junho-Setembro de 2016 - ISSN 1984-9605 - p. 
Ao professor Pedro, de quem fui orientando de mestrado e de doutorado, meu reconhecimento na forma desta modesta homenagem.

\section{Considerações iniciais}

obra intelectual de Pedro Goergen vem marcada por uma forte
influência da Teoria Crítica, de modo especial, do
redirecionamento que nela ocorre com as reflexões desenvolvidas por Habermas. Considerando tal influência, o presente texto procura trazer à tona algumas reflexões sobre a teoria da racionalidade comunicativa de Habermas e explicitar, de forma mais específica, os argumentos que levam o filósofo alemão a considerar em sua teoria de agir comunicativo, o mundo da vida como fonte que assegura a racionalidade cognitiva, a validade normativa das ações dos indivíduos e o potencial emancipador da sociedade. Com efeito, conforme constata Goergen, "o conceito de ação comunicativa não pode ser entendido sem o complemento necessário que Habermas denomina de mundo da vida" (2004, p. 124). E complementa Goergen: "Numa palavra, o mundo da vida é o saber de fundo comunicativamente estruturado, a partir do qual ordenamos nossos processos de entendimento e justificamos nossas ações" (2004, p. 125).

É a partir dos anos 1980, que Habermas começa a atribuir um papel fundamental ao mundo da vida, passando a considerá-lo como fonte de um tipo racionalidade - a racionalidade comunicativa - capaz de se opor ao processo de dominação sistêmica e manter a autonomia dos indivíduos, pela busca do entendimento. Mas é em suas últimas obras e ao retomar o tema do conhecimento que ele busca retificar sua visão de verdade e normatividade consensual assentada sobre condições linguísticas idealizadas (condição 
ideal de fala), encontrando na pragmática do mundo da vida a condição real para tal fim. São as relações morais e cognitivas com o mundo, justificadas pragmaticamente, que produzem as certezas e os valores que orientam as ações dos indivíduos. O mundo da vida é a realidade objetiva, composto de certezas e normas válidas que somente são tematizadas pelo discurso quando se tornam problemáticas. Ao serem submetidas à análise, as certezas existentes tornam possível o surgimento de uma nova verdade, ou de um novo valor. É esse fluxo contínuo, em que as certezas se tornam incertas e depois retornam sob forma de novas certezas, que possibilita o esclarecimento e realiza a emancipação humana.

A reflexão desenvolvida no texto destaca, num primeiro momento, a retomada do conceito de mundo da vida na obra do autor, procurando esclarecer o papel que ele atribui a essa instância em diferentes momentos de sua teoria e, de modo especial, nos seus últimos trabalhos. Num segundo momento, são desenvolvidos, sinteticamente, os principais argumentos aos quais o autor recorre para fundamentar a validade e a objetividade do conhecimento desenvolvido pragmaticamente no mundo da vida. $\mathrm{Na}$ sequência, o texto trata de esclarecer o entendimento de Habermas sobre a validade normativa das ações e procura destacar o caráter emancipador da sociedade sustentada no exercício da comunicação, desde sempre presente no mundo da vida.

\section{O tema do mundo da vida na obra de Habermas}

A preocupação em mostrar a centralidade do mundo da vida na constituição da realidade social, tem marcado a caminhada intelectual de Habermas desde o posfácio de "Conhecimento e interesse" (1982), estendendo-se pelas obras "A lógica das Ciências Sociais" (2007) e "Teoria de la acción comunicativa" (1987, 2 v.), chegando às suas obras mais recentes,

Filosofia e Educação [RFE] - Volume 8, Número 2 - Campinas, SP Junho-Setembro de 2016 - ISSN 1984-9605 - p. 97-120 
especialmente "Pensamento pós-metafísico" (1990) e "Verdade e justificação" (2004) $)^{1}$.

No presente texto, nossa análise se centrará, especialmente, em quatro de suas obras que tratam do tema: "A lógica das Ciências Sociais" (LCS), "Teoria da ação comunicativa" (TAC), "Pensamento pós-metafísico" (PPM) e "Verdade e justificação" (VJ). Em LCS e TAC, Habermas atribui um papel central ao mundo da vida, passando a considerá-lo como fonte de um tipo racionalidade - a racionalidade comunicativa - capaz de se opor ao processo de dominação sistêmica e manter a autonomia dos indivíduos pela busca do entendimento. Enquanto na LCS ele inicia o desenvolvimento de uma breve arqueologia do mundo da vida com base nos trabalhos de Husserl, Heidegger, Wittgenstein, Gadamer e Schütz, procurando mostrar as limitações das concepções empírico-analíticas do conhecimento e a pertinência das estruturas simbólicas e interpretativas no campo das ciências sociais, em TAC ele amplia e aprofunda a discussão sobre a centralidade do mundo da vida, sustentando-se na exploração de autores como Georg $\mathrm{H}$. Mead, Peter Berger e Thomas Luckmann, Austin e Searle, bem como procura comprovar a constituição das ações sociais nas regras gramaticais de interação comunicativa. Nas obras PPM e VJ, o autor articula o mundo da vida de forma mais clara com o problema do conhecimento e de sua justificação e validação. Nesta última obra, de modo especial, ele passa a afirmar que o saber produzido no mundo da vida fundamenta-se numa

1 Habermas desenvolve importante análise da relação entre mundo da vida e direito em "Direito e democracia: entre facticidade e validade" (1997, 2 volumes), destacando a insuficiência da racionalidade comunicativa predominante no mundo da vida para promover a democratização da sociedade e atribuindo um papel importante ao direito como um recurso indispensável para formação dessa sociedade democrática. Não temos condições, pelo limite do presente trabalho, de analisar a posição de Habermas nesta obra, mas cabe ponderar que se trata de um campo da ação humana vinculada, de forma mais imediata e direta, com o mundo sistêmico, situação que não se apresenta da mesma forma quando tratamos da educação.

Filosofia e Educação [RFE] - Volume 8, Número 2 - Campinas, SP

Junho-Setembro de 2016 - ISSN 1984-9605 - p. 97-120 
autoridade cognitiva que se constitui naturalmente pela ação daqueles que buscam um entendimento acerca do mundo e uma normatividade para seus atos. O saber que se desenvolve na prática cotidiana não é um saber, a princípio, falso, ideológico, parcial - como aparece em passagens de textos anteriores -, mas um saber que mantém uma relação intrínseca com a verdade. De agora em diante, o mundo da vida assume uma dimensão ampliada na interpretação que Habermas desenvolve sobre o conhecimento e sua validade cognitiva e normativa.

A tese central de Habermas em VJ sustenta-se na concepção de que o mundo da vida é portador de verdade que, enquanto não colocada em questionamento, é absoluta e incondicionada. À medida que ele passa a assumir uma postura mais radicalmente pragmatista de verdade, a objetividade do mundo que servia de base para a validação dos conhecimentos na teoria epistemológica cede lugar para as evidências do mundo da vida, evidências que sempre são estruturadas por idealizações de natureza universal. Cabe destacar que, se em Conhecimento e interesse (CI) e em outros textos da fase inicial da vida intelectual do autor, o mundo da vida é refúgio de falsa consciência e de ideologias, nas obras mais recentes ele passa a ser tratado como fonte geradora das idealizações que tornam possível o surgimento das verdades e dos valores de natureza universal. Conforme ele mesmo afirma, o mundo da vida vive de "um adiantamento de validez, proporcionado por certezas consentidas preliminarmente" (1990, p. 89). Em outros termos, o mundo da vida já se encontra, em certo sentido, na verdade e é fonte de certezas que se mantêm válidas enquanto responderem às expectativas e necessidades de todos os envolvidos. Nos termos do próprio autor:

Filosofia e Educação [RFE] - Volume 8, Número 2 - Campinas, SP Junho-Setembro de 2016 - ISSN 1984-9605 - p. 97-120 
O mundo da vida comum em cada caso oferece uma provisão de obviedades culturais donde os participantes da comunicação tiram seus esforços de interpretação nos modelos de exegeses consentidos (1989, p. 166).

E em texto posterior complementa:

As práticas do mundo da vida são sustentadas por uma consciência plena de certezas que, in actu, não deixa nenhum espaço para reservas quanto à verdade. [...]. No trato prático com um mundo objetivo suposto como idêntico e independente, os atores dependem de certezas de ação (2004, p. 49, grifo do autor)

Para entender sua posição, precisamos atentar para a argumentação que Habermas apresenta sobre o desenvolvimento da racionalização do mundo da vida. Segundo ele, as certezas do mundo da vida e suas idealizações como verdades absolutas somente são tematizadas quando práticas malsucedidas ou contradições emergentes colocam em crise as obviedades tidas como inquestionáveis. Ou seja, somente quando as relações rotineiras do mundo da vida se tornam problemáticas é que os participantes deste mundo assumem uma atitude reflexiva e procuram desenvolver argumentos que possam explicar e justificar a situação vivenciada como problemática. Em tal situação, ocorre o que Habermas denomina a passagem da ação comunicativa para o discurso, circunstância em que o problema da verdade deixa de ser algo "óbvio" e passa a se constituir como um problema de justificação racional através da argumentação. Nesse caso, a aceitabilidade racional que se fazia presente na produção e reprodução do mundo da vida cede lugar ao discurso. O discurso tem a função de reparar as distorções e as perturbações que colocam em 
crise o funcionamento normal do mundo da vida. O discurso, porém, não é uma prática que se mantém por muito tempo na vida cotidiana. Depois de restabelecer o acordo de fundo que se achava perturbado, o discurso deixa de ter função, e o entendimento do mundo da vida volta a orientar-se por um trato ingênuo com o mundo (cf. HABERMAS, 2004, p. 50).

Cabe destacar que, com essa nova postura, Habermas não desconsidera a importância dos conhecimentos científicos acumulados pela humanidade e observa que um dos pressupostos fundamentais para a emancipação humana é a apropriação crítica dos conhecimentos produzidos. Ademais, o fato de insistir no poder constituinte do saber que emerge do mundo da vida e de destacá-lo como foro de validação de saber que acaba se constituindo em "conhecimento verdadeiro", não nos autoriza afirmar que a fala normal do dia a dia e a compreensão que se apresenta de forma imediata no mundo da vida sejam razões suficientes para a concretização de uma comunicação isenta de perturbações. A compreensão hermenêutica é um passo importante, mas insuficiente para o estabelecimento de uma comunicação não distorcida e para a superação das patologias sociais ${ }^{2}$. As pretensões de validez dos conhecimentos humanos não são imanentes a toda e qualquer manifestação do mundo da vida, e não é pelo fato de os indivíduos possuírem a habilidade natural de fala que seus saberes são necessariamente verdadeiros, autênticos e corretos. $\mathrm{O}$ fato de um saber ser linguisticamente articulado e intersubjetivamente constituído não lhe garante ainda sua veracidade. Para tanto, é preciso buscar sustentação em uma realidade objetiva, que, no entender de Habermas, somente pode ser a certeza constitutiva do mundo da vida. Certeza que, aliás, não é hipotética, mas categórica.

2 As críticas de Habermas em relação à hermenêutica, especialmente em relação a Gadamer, encontram-se desenvolvidas em "A pretensão de universalidade da hermenêutica" (1987).

Filosofia e Educação [RFE] - Volume 8, Número 2 - Campinas, SP Junho-Setembro de 2016 - ISSN 1984-9605 - p. 97-120 
Habermas posiciona-se contra a concepção de uma assimilação ingênua dos conhecimentos e dos saberes advindos da tradição e pondera que a veracidade dos conhecimentos do mundo da vida não pode ser obtida mediante razões e argumentos. Ou seja, todo manancial de saberes que o mundo da vida possa apresentar não pode ser justificado apenas em vista da explicitação clara dos significados ou pela coerção do melhor argumento, pois também neste podemos nos enganar e acabar aceitando visões distorcidas e parciais da realidade. Nesse sentido, nenhum saber - seja ele científico, ético, estético - pode ser validado, exclusivamente, pela inteligibilidade ou pela clareza de sentido que apresenta na sua justificação. Ou seja, embora o critério da inteligibilidade e a expressão clara do sentido devam ser considerados como aspectos preliminares indispensáveis do processo do entendimento, eles, por si mesmos, não garantem a validação de um determinado conhecimento ou um determinado valor. Para o autor, a validade de qualquer saber depende, sempre de novo, da possibilidade de justificação da sua validez diante das exigências de um saber de fundo do mundo da vida. Ainda que sempre falível, o saber cotidiano acaba assumindo a condição de verdade que orienta nossa ação e nosso comportamento. Todo o conhecimento é validade por um mundo idêntico e intransponível.

A posição de Habermas alerta para um duplo aspecto em relação aos conhecimentos humanos: em primeiro lugar, a necessidade de que todo o conhecimento seja entendido enquanto parte do mundo da vida, dependendo a compreensão de seu sentido, isto é, sua inteligibilidade, do desenvolvimento de sua análise hermenêutica; em segundo lugar, que mesmo o entendimento do sentido obtido pelo exercício hermenêutico não é suficiente para se chegar à veracidade do fato, sendo preciso colocar, a cada instante, o conhecimento sob a apreciação de sua eficácia pragmática de se 
manter como um saber válido na produção e reprodução do mundo da vida. Isso representa a necessidade de politizar novamente o saber e de colocá-lo permanentemente ao julgamento público. Somente permitindo o questionamento permanente dos saberes que tornam possível a reprodução do mundo da vida é que a educação poderá contribuir para a inovação do conhecimento e ajudar no aperfeiçoamento das vivências sociais. Essa visão epistemológica pode trazer importantes contribuições para o campo educacional as quais precisam ser explicitadas.

\section{A universalidade e validade cognitiva do mundo da vida}

A partir da virada pragmática assumida por Habermas, o mundo da vida torna-se "não somente o fundamento de nossa crença na realidade do mundo exterior", sendo, também, “o depositário de fontes suscetíveis de contribuir para o processo de discussão racional sobre a verdade" (PICHÉ, 2003, p. 26). O mundo da vida assume a condição de objetividade que torna possível a comunicação e o entendimento entre os sujeitos da interação. Esse "realismo" do mundo da vida é a condição para que o entendimento possa ser obtido, conforme o próprio filósofo afirma:

Visto que os autores precisam chegar a um bom termo com "o" mundo, eles não podem evitar ser realistas no contexto de seu mundo da vida. E eles têm o direito de sê-lo, pois seus jogos de linguagem e práticas, enquanto funcionam imunes a decepções, "resistem à prova" na própria execução. [...]. A orientação pela verdade incondicional, que força os interlocutores à suposição de condições ideais de justificação e a uma descentração cada vez mais expandida da comunidade de justificação, é um reflexo dessa outra distinção indispensável no mundo da vida - que separa a opinião do saber e se

Filosofia e Educação [RFE] - Volume 8, Número 2 - Campinas, SP Junho-Setembro de 2016 - ISSN 1984-9605 - p. 97-120 
apoia na suposição de um único mundo objetivo, suposição ancorada no uso comunicativo da linguagem (HABERMAS, 2004, p. 257-258).

Habermas parte do pressuposto que o conhecimento do mundo da vida tem um caráter de validação universal. Ao ser construído pelo agir comunicativo, apresenta as condições de uma verdade de natureza universal e incondicionada e, por isso, suscetível de ser sempre, mesmo que questionado, revalidado. A princípio, o mundo da vida desde sempre já se constitui em um horizonte de convicções comuns e indubitáveis, comportando conhecimentos não problematizados e inquestionavelmente certos. Esses conhecimentos não são ilusórios, nem falsos, uma vez que se constituem a partir de um "adiantamento de validez, proporcionado por certezas consentidas preliminarmente, ou seja, por certezas do mundo da vida" (1990, p. 89). Em outros termos, "o próprio solo da prática comunicativa cotidiana descansa sobre pressupostos idealizadores" (1990, p. $88)$.

A sustentação da dimensão universalizadora do saber do mundo da vida é fundamentada por Habermas no poder que a prática comunicativa nela atuante tem de constituir e desenvolver três planos de ação: 1- de transmitir e renovar o saber cultural; 2- de coordenar a ação e de promover a integração social; e 3- de possibilitar a formação das identidades pessoais (cf. HABERMAS, 1987b, p. 196). Em outros termos, a prática comunicativa presente no cotidiano do mundo da vida é o meio através do qual se reproduzem a cultura, a sociedade e a personalidade sob orientação de uma noção de verdade incondicional, independente do contexto. O mundo da vida tem, portanto, um poder de instituir e de legitimar os seus próprios saberes, embora tal validade o transcenda. Em síntese, o mundo da vida 
apresenta estruturas vividas que, por sua condição comunicativa, são racionais e objetivas.

Habermas aprofunda suas reflexões destacando que as proposições são legitimadas pela coerência com o mundo da vida e com outras proposições e que a verdade de um argumento depende da sua aceitabilidade pública, o que permite assegurar que os argumentos apresentados de forma justificada e coerente são a acessibilidade ao horizonte do mundo linguístico revelado no mundo da vida. Isso, porém, não o leva a considerar que a verdade pode ser identificada com as certezas do mundo da vida de forma absoluta e definitiva; a verdade só se mantém como verdade até ser encaminhada para o nível discursivo e ser novamente reavaliada pela comunidade argumentativa. A verdade, produzida de forma cooperativa pelo discurso, pode oferecer confiança às práticas cotidianas e manter-se como verdade por um determinado tempo. Mas nada assegurará sua validade. A qualquer momento poderá ser questionada, caso não sirva mais para assegurar a reprodução do mundo da vida. Essa permanente capacidade de revalidação da verdade que se realiza no mundo da vida é atribuída por Habermas à condição quase transcendental que a linguagem apresenta.

Habermas é um adepto do falibilismo do conhecimento, mas isso não o leva a concordar com o relativismo defendido por alguns pensadores pósmodernos que negam a possibilidade da validação do conhecimento além de seu uso em um contexto específico. São inúmeros os debates que ele realiza defendendo a validez dos saberes desenvolvidos pelos indivíduos na prática comunicativa cotidiana, procurando revelar o caráter de validade e de universalidade que apresentam. Para esclarecer sua posição, o pensador alemão retoma a questão da relação entre verdade, objetividade e linguagem. Para Habermas, a ciência somente pode desenvolver-se sob o pressuposto de um conhecimento sustentado na ideia de uma "experiência 
objetiva" que tem na referência a uma "realidade objetiva" o critério último de validação do conhecimento científico. Em Habermas ${ }^{3}$, essa objetividade da experiência não é negada como critério de validação, mas articulada à espontaneidade geradora da linguagem que se desenvolve no mundo da vida. Ou seja, depois da virada linguística, a objetividade que as ciências reivindicam já não pode ser buscada em uma realidade externa ou em uma realidade ontológica alheia, mas na objetividade que os autores em interação estabelecem no mundo da vida. Com a destranscendentalização, o mundo da vida assume o lugar do mundo numênico e apresenta uma objetividade plena de certezas que não deixa dúvidas quanto à verdade. $\mathrm{O}$ mundo da vida é algo absolutamente real, normativamente estruturado por regras e, como tal, fonte de evidências que são concebidas como justificáveis e certas até o momento que sobrevenha um distúrbio ou um conflito. Em síntese, a objetividade do mundo da vida atende desde sempre a duas exigências imprescindíveis na constituição da verdade: um determinado índice de realidade e uma pretensão de saber absoluto, não condicional. A primeira manifesta-se na certeza constitutiva do mundo da vida; a segunda, na experiência objetiva das verdades cotidianas.

Na sequência de sua argumentação, Habermas esclarece que a fonte originária que provoca o surgimento das ciências não é a lógica da pesquisa científica, mas a exigência de esclarecimento que se faz presente no próprio mundo da vida. "Mesmo os enunciados verdadeiros podem concretizar apenas as possibilidades cognitivas que nos são, de modo geral, abertas por formas de vida socioculturais" (2004, p. 16). Os objetos do nosso conhecimento recebem, portanto, seu status de inteligibilidade nas

3 Habermas reconhece que a teoria de verdade que ele havia desenvolvido em textos anteriores carece de um referencial objetivo de validação, pois a simples justificação racional por argumentos é insuficiente para validar o conhecimento. Em "Verdade e justificação", ele encontra um ponto de ancoragem de validação na objetividade que os autores em interação estabelecem no mundo da vida.

Filosofia e Educação [RFE] - Volume 8, Número 2 - Campinas, SP

Junho-Setembro de 2016 - ISSN 1984-9605 - p. 97-120 
estruturas do nosso mundo da vida, o qual sempre é regido por regras universais e por evidências que são absolutamente verdadeiras até que sejam problematizadas por um distúrbio ou práticas malsucedidas.

O progresso técnico e o conhecimento científico não têm uma legitimidade própria, nem um poder de autodeterminação infinito. As decisões acerca dos processos científicos não seguem, exclusivamente, determinações técnicas, nem são determinadas por necessidades objetivas, ou por leis naturais isentas de justificações intersubjetivas. A alegação do caráter de objetividade e neutralidade da ciência e da técnica deve-se à sua redução como mecanismos de poder e instrumentos ideológicos de controle e dominação; nesse caso, ciência e técnica seguem determinações que nascem de interesses inerentes ao dinheiro e ao poder. Somente desmitificando o seu caráter ideológico, ciência e técnica poderão assumir uma nova significação social.

A ciência e a técnica mantêm uma inevitável acoplagem ao mundo da vida. O mundo da vida é o contexto de origem das esferas da ciência, do direito, da ética e da estética; ou seja, sobre as experiências pré-científicas do mundo da vida é que são, originariamente, constituídas todas essas instâncias de saber. Por maior que seja a objetividade que apresentem e por mais autônomas que elas se revelem, é no mundo da vida que cada uma dessas instâncias encontra seu fórum de validação; o mundo da vida é o pano de fundo em que os saberes são postos à prova e recebem seu selo de inteligibilidade, de validade e de confiabilidade. Antes mesmo que se torne um desafio para as ciências, a verdade já é uma pretensão no mundo cotidiano da vida; antes que um saber se transforme em saber científico, ele é um saber preliminarmente instituído como verdadeiro e validado no mundo da vida. Em decorrência disso, o mundo da vida tem um "primado 
ôntico-ontológico" (HABERMAS, 1996, p. 65) sobre as ciências e sobre os saberes dos especialistas.

Como podemos perceber, a justificação das ações dos indivíduos no mundo da vida vem sempre orientada por uma verdade, tida como tal, que transcende a própria justificação e se torna eficaz na ação. Desde sempre, o mundo da vida compreende dimensões de racionalidade que possibilitam o surgimento de um saber verdadeiro e incondicional.

Cabe destacar, porém, que, ao valorizar o conhecimento espontâneo do mundo da vida, Habermas não está desconsiderando a importância da "estruturação procedimental criadora" do conhecimento científico e das outras instâncias do saber. Isso ele esclarece quando escreve sobre a necessidade de que o saber que orienta o mundo da vida passe pelo crivo da crítica e seja sempre validado através do critério do melhor argumento. A mesma ponderação ele faz quando fala dos papéis da filosofia e da ciência no contexto da sociedade atual:

Nunca faz bem à filosofia romper a cooperação com as ciências e obstinar-se numa esfera além das ciências [...]. Sem o contato científico ou sem o trabalho em problemas gerados no interior das disciplinas, a filosofia perde as descobertas próprias de que precisa para poder preencher seus papéis exotéricos (HABERMAS, 2004, p. 321-322).

O pensador alemão considera a ciência como uma importante conquista humana, sendo indispensável para o desenvolvimento de uma sociedade emancipada. Uma qualificada apropriação crítica dos conhecimentos torna-se, por isso, condição imprescindível para o desenvolvimento social. A ciência, a partir da modernidade, não é mais um elemento complementar da formação humana; por isso, não pode deixar de 
fazer parte do processo da formação da sociedade moderna. Isso não implica dizer que a ciência deva ser transformada na única razão de ser da escola, rechaçando-se, em nome de uma visão estreita de formação cientificista, a necessidade da ilustração e do desenvolvimento do senso crítico e criativo.

Deve-se ponderar, porém, que, se de um lado não podemos desconsiderar o avanço científico e técnico e aceitar o fato de que mundo se apresenta cada vez mais configurado cientificamente, de outro não nos cabe deixar de acolher tal fato, analisando com rigor e profundidade as consequências que um desenvolvimento unilateral, cientificista pode trazer. A partir de Habermas, podemos inferir que a formação escolar não pode deixar de ser, concomitantemente, científico-téenica e ético-política. Ela deve preocupar-se em exercer um papel mediador entre a formação técnica e científica e a formação humana. Sua tarefa consiste em minorar a distância entre as grandes massas e a elite de investigadores, evitando o distanciamento do processo de desenvolvimento técnico do campo das discussões do mundo da vida e de sua validação ética. Acima de tudo, cabelhe a tarefa de fortalecer o poder de resistência do mundo da vida contra a dominação sistêmica que se desenvolve através de determinado tipo de racionalidade científica.

Em outros termos, a aprendizagem científica deve vir acompanhada da análise de suas consequências objetivas sobre a vida cotidiana e julgada por princípios de validade universal, construídos consensualmente. Junto à configuração do mundo objetivo, regido progressivamente por critérios científicos e racionais, deve configurar-se uma sociedade cada vez mais livre e autorregida por princípios de racionalidade desenvolvida intersubjetivamente no contexto do mundo da vida. Ainda que as diferentes instâncias do mundo da vida atinjam uma dimensão de racionalidades cada vez mais especializadas, elas não se podem desvencilhar totalmente do 
mundo da vida, sob o risco de se tornarem recursos de colonização. A manutenção da articulação constante com o mundo da vida é que irá assegurar o desenvolvimento de uma racionalização emancipadora do mundo.

Habermas defende a tese de que, junto à configuração do mundo objetivo, regido progressivamente por critérios científicos e racionais, deve configurar-se uma sociedade cada vez mais livre e autorregida por princípios de uma racionalidade que se desenvolve intersubjetivamente no contexto do mundo da vida. Ainda que atinjam uma dimensão de racionalidades cada vez mais especializadas, as diferentes instâncias do mundo da vida não podem desvencilhar-se totalmente do mundo da vida, sob o risco de se tornarem recursos de colonização. A manutenção da articulação constante com o mundo da vida é que irá assegurar o desenvolvimento de uma racionalização emancipadora do mundo.

O mundo da vida assume, portanto, a condição de autoridade cognitiva e deve deixar de ser entendido como espaço da falsa consciência, de visões distorcidas da realidade e de ideologias. Para Habermas, "o mundo da vida constitui o horizonte de uma práxis do entendimento mútuo, em que os sujeitos que agem comunicativamente procuram, em conjunto, chegar a bom termo com seus problemas cotidianos" (2004, p. 320).

\section{Racionalidade, validade normativa e emancipação}

O mundo da vida, além de sustentar-se na validade cognitiva de seus conhecimentos, reproduz-se sob a exigência de duas outras dimensões importantes: a validade normativa das ações dos sujeitos e o caráter emancipador da sociedade sustentada no exercício da comunicação ${ }^{4}$.

4 Habermas desenvolve essa discussão, de modo específico, no capítulo intitulado "Correção versus verdade", em "Verdade e justificação" (2004, p. 267-310) 
No entender de Habermas, o saber produzido no mundo da vida fundamenta-se, desde sempre, numa autoridade cognitiva e moral que se realiza naturalmente à medida que os indivíduos buscam um entendimento acerca dos fatos e uma normatividade para seus atos. "Os sujeitos capazes de falar e agir aprendem no decorrer de sua socialização as práticas fundamentais de seu mundo da vida e o correspondente saber relativo às regras" (HABERMAS, 2004, p. 25). Por isso, o saber que se desenvolve na prática cotidiana não pode ser considerado como falso, ideológico, parcial, privado, mas um saber que já é, desde o princípio racional, verdadeiro, orientado por pretensões de validez que o submetem a uma avaliação permanente, tanto no aspecto cognitivo, quanto no aspecto normativo.

Ao agirem comunicativamente no mundo da vida, os sujeitos sempre se orientam normativamente, pois buscam cumprir normas que asseguram a possibilidade do entendimento: "já no dia a dia, o jogo linguístico moral nos enreda numa disputa conduzida com base em razões" (HABERMAS, 2004, p. 306). À semelhança do que ocorre quando se estabelece um entendimento acerca de uma realidade objetiva, os sujeitos em interação estabelecem acordos acerca de regras normativas que tornam possível a interação e a manutenção de grupos, de instituições e da própria sociedade. ${ }^{5} \mathrm{~A}$ regra fundamental da interação que se estabelece no mundo da vida quando um consenso precisa ser buscado é "a sensibilização recíproca dos participantes para a compreensão que o outro tem do mundo e de si mesmo" (2004, p. 303). Isso porque "a força suave dos pressupostos inevitáveis da argumentação exige dos envolvidos a adoção da perspectiva de todos os outros, bem como a consideração dos seus interesses" (2004, p. 300). As

5 Cabe ressaltar que, mesmo que existam semelhanças entre o processo de construção de uma verdade no plano do conhecimento e a construção de uma norma, também existem diferenças que precisam ser consideradas. Habermas esclarece tais diferenças no texto "Correção versus verdade" (2004).

Filosofia e Educação [RFE] - Volume 8, Número 2 - Campinas, SP Junho-Setembro de 2016 - ISSN 1984-9605 - p. 97-120 
normas morais do mundo da vida são geradas, portanto, pelo reconhecimento de regras que corporificam interesses comuns e atendem as perspectivas de todos os envolvidos. Em outros termos, as normas assumem a condição de universalidade porquanto corporificam interesses comuns a partir da perspectiva de um "nós". Não temos outro espaço para desenvolver tal processo, a não ser o contexto do mundo da vida.

Habermas esclarece que o processo de individuação e formação de uma identidade subjetiva autônoma e eticamente responsável não é anterior ao processo de socialização, mas decorre do nível de socialização que já se encontra desenvolvido no mundo da vida. Ou seja, o desenvolvimento ético do indivíduo e a emancipação só podem ocorrer sob a orientação de evolução da racionalidade comunicativa do mundo da vida.

Aos indivíduos, o processo a partir do qual o mundo da vida se emancipa das tradições apresenta-se primeiramente como uma diferenciação progressiva, vivida como um destino, de situações de vida diversificadas e expectativas de comportamento conflituosas que os sobrecarregam com novos esforços de coordenação e integração (HABERMAS, 2010, p. 256-257).

No entendimento do pensador alemão, são as exigências demandadas do mundo da vida em sua evolução que fazem emergir a identidade de um eu pós-convencional, de uma individualidade autônoma, de uma subjetividade ética:

O auto - da autocompreensão ética - depende do reconhecimento por parte de destinatários, e constitui-se primeiramente como resposta às exigências de um adversário. Na medida em que os outros pressupõem a minha capacidade de responder pelas minhas acções, eu faço de mim

Filosofia e Educação [RFE] - Volume 8, Número 2 - Campinas, SP Junho-Setembro de 2016 - ISSN 1984-9605 - p. 97-120 
mesmo, passo a passo, aquele em que me tornei na convivência com os outros. Não posso manter apenas pela minha força própria o Eu que me parece ser dado, na minha autoconsciência, como um bem absolutamente próprio - ele não me "pertence". Este Eu conserva, antes, um núcleo intersubjetivo, porque o processo de individuação de que provém atravessa a rede das interações mediadas pela linguagem (2010, p. 232).

A exposição acima revela que tanto a construção dos conhecimentos como a formação das individualidades autônomas, emancipadas são decorrentes de práticas coletivas de interação. São os sujeitos capazes de linguagem e ação que, introduzindo-se em um mundo da vida intersubjetivamente compartilhado, desenvolvem seus saberes e definem suas identidades. O indivíduo só desenvolve um "centro interior" à medida que estabelece relações interpessoais que se dão pela comunicação.

O mundo da vida é a instância em que ocorrem todos os processos de reprodução fundamentais à subsistência da espécie humana. Assim, nele são desenvolvidos de igual forma conhecimentos, normas e valores que irão orientar e sustentar o agir dos sujeitos na relação com os outros. Tais normas ou valores somente serão submetidos a um julgamento discursivo no momento em que se tornarem problemáticos, quando já não conseguem assegurar a adequada reprodução do mundo da vida. A suspensão, porém, é sempre momentânea, e tão logo for restabelecido o entendimento, tornam a atuar no mundo da vida como normas e valores válidos, eficazes. Por isso, segundo Habermas, não podemos deixar de levar em consideração as formas de vida e as instituições que são praticadas e reconhecidas numa sociedade específica como justas e legítimas. 
A validade da norma só pode ser sustentada, portanto, se forem respeitados os princípios orientadores da racionalidade comunicativa e da ética discursiva, que, segundo Habermas, são dois. O primeiro é o princípio da universalização (princípio "U”) e estabelece:

[...] toda norma válida deve satisfazer a condição de que as consequências e efeitos colaterais, que (previsivelmente) resultarem para a satisfação dos interesses de cada um dos indivíduos do fato de ser ela universalmente seguida, possam ser aceitos por todos os concernidos $(1989$, p. 86).

O segundo princípio, do discurso (princípio “D”), por sua vez, afirma: "Só podem reclamar validez as normas que encontrem (ou possam encontrar) o assentimento de todos os concernidos enquanto participantes de um discurso prático" (1989, p. 116). Tais princípios não só possibilitam a constituição legítima do mundo da vida como também asseguram a única forma de orientação racionalmente admissível para a resolução dos conflitos que acaso possam ocorrer tanto no mundo da vida quanto na sociedade.

Cabe ressaltar, porém, que o consenso que se produz acerca da validade das normas sob a condução do princípio da universalidade não pode ser satisfeito somente no discurso. Ele deve ser seguido pela aplicação prática das normas, cujo critério de avaliação torna a ser a "adequação" às demandas do mundo da vida. O mundo da vida passa a se constituir, portanto, como a instância última de validação dos valores e dos saberes de toda a sociedade. Mesmo depois de passar pela discussão pública por meio do discurso, cabe ao mundo da vida dar a última palavra sobre a legitimidade do saber e a validade da norma.

Filosofia e Educação [RFE] - Volume 8, Número 2 - Campinas, SP Junho-Setembro de 2016 - ISSN 1984-9605 - p. 97-120 
Habermas considera que a garantia da manutenção de uma sociedade democrática depende, em última instância, da preservação do mecanismo fundamental de reprodução do mundo da vida: a interação comunicativa. Daí seu esforço de mostrar como o mundo da vida pode preservar um princípio de autonomia num nível público de normatividade e universalidade, mantendo a integração e a diferenciação de instituições tais como a família, a sociedade civil, o Estado e as organizações governamentais e não governamentais, com relação aos subsistemas econômicos, políticos e administrativos. A facticidade do mundo da vida, que, em particular, expressa uma cultura política democrática pluralista, precisa ser compreendida de maneira correlata à normatividade e validade da autonomia pública. No entender de Habermas, os fundamentos necessários para uma autodeterminação capaz de realizar o projeto modernista de emancipação, embasado na razão comunicativa, devem integrar a vida social cotidiana e as diferentes instâncias do mundo.

\section{Considerações finais}

Pensamos ter esclarecido a razão que leva Habermas a atribuir o papel determinante ao mundo da vida na constituição de uma sociedade democrática e emancipada e na formação de indivíduos autônomos e responsáveis. Como podemos perceber, toda a explicação de Habermas lança-se a partir da atitude procedimental que constitui a formação do mundo da vida. É o exercício da prática cotidiana da comunicação na busca do entendimento que assegura a formação de indivíduos que vão possibilitar a surgimento de sociedades democráticas. Estas, por sua vez, exigirão o surgimento de sujeitos autônomos e eticamente responsáveis.

No mundo da vida, a verdade e a retidão do agir resolvem-se, de modo geral, por meio de discursos teóricos e práticos, tendo os fatores sistêmicos, 
como o dinheiro e o poder, apenas um papel secundário nesse processo. A solução dos problemas da coerência das intenções ou das motivações realiza-se por intermédio das ações coerentes dos indivíduos em interação, na busca do entendimento. Portanto, o critério de coerência envolve o problema das exigências reais dos indivíduos, as quais dizem respeito às necessidades vitais de cada parceiro da comunicação, da sua autopreservação e do reconhecimento social de que necessita.

Em razão disso, a avaliação dos conhecimentos e dos comportamentos dos indivíduos no espaço do mundo da vida sempre é feita na perspectiva de não serem debilitadoras e falaciosas em relação ao que se encontra instituído no mundo da vida. No contexto do mundo da vida, não há possibilidade de arrancar os conhecimentos, os comportamentos e as ações estéticas de suas relações com a ação comunicativa; no horizonte do mundo da vida, a verdade, a retidão, a expressão têm uma íntima vinculação com a ordem social instituída e com os valores aí predominantes. Por isso, qualquer conhecimento ou qualquer comportamento nunca é visto como "sem sentido" ou como "sem valor"; tudo se atrela ao compromisso com o modo de ser, pensar e viver do grupo ou da comunidade.

No entender de Habermas, o mundo da vida constitui-se sempre por uma prática de integração hermenêutico-deliberativa, e por isso podemos encontrar na forma de sua realização referenciais teóricos e práticos capazes de possibilitar a emergência de uma sociedade verdadeiramente democrática. Tal constatação explica o esforço do filósofo em demonstrar a importância que o contexto cotidiano do agir e da comunicação está tomando na orientação do desenvolvimento das ciências sociais e da própria educação. Segundo sua posição, é impossível avançar nas questões da prática social emancipadora sem que se leve em consideração a influência 
que o mundo da vida exerce no modo de ser, sentir e pensar das pessoas e nas relações entre os diferentes atores que agem nesse meio.

\section{Referências}

GOERGEN, P. L. Teoria da ação comunicativa e práxis pedagógica. In: DALBOSCO, C. A.; LONGHI, S. M.; TROMBETTA, G. (orgs.). Sobre filosofia $e$ educação: subjetividade-intersubjetividade na fundamentação da práxis pedagógica. Passo Fundo: Ed. Universidade de Passo Fundo, 2004. p. 111-151. 222

HABERMAS, J. Conbecimento e interesse. Rio de Janeiro: Jorge Zahar, 1982.

A pretensão de universalidade da hermenêutica. In: HABERMAS, J. Dialética e hermenêutica. Trad. Álvaro L. M. Valls. Porto Alegre: L\&PM, 1987. p. 26-72.

Consciência moral e agir comunicativo. Rio de Janeiro: Tempo Brasileiro, 1989.

Pensamento pós-metafísico. São Paulo: Tempo Brasileiro, 1990.

Teoria de la acción comunicativa I: racionalidad de la acción y racionalización social. Madrid: Taurus, 1987a.

Teoria de la acción comunicativa II: crítica de la razón funcionalista. Madrid: Taurus, 1987b.

- Edmundo Husserl sobre mundo de la vida, filosofia y ciência. In: REDONDO, M. J. (org.). Textos y contextos. Barcelona: Ariel, 1996. p. 59-73.

Direito e democracia: entre facticidade e validade. Rio de Janeiro: Tempo Brasileiro, 1997. v. 2.

Verdade e justificação: ensaios filosóficos. São Paulo: Loyola, 2004.

Fundamentos linguísticos da sociologia. Lisboa: Edições 70, 2010. (Obras escolhidas, v.1)

Filosofia e Educação [RFE] - Volume 8, Número 2 - Campinas, SP Junho-Setembro de 2016 - ISSN 1984-9605 - p. 97-120 
MÜHL, E. H. Vida, mundo da vida e educação: uma leitura habermasiana do problema da justificação da ação educativa. In: TREVISAN, A. L.; TOMAZETTTI, E. M.; ROSSATTO, N. D. (orgs.). Diferença, cultura e educaşão. Porto Alegre: Sulina, 2010. p. 240-253.

; GOMES, L.R; ZUIN, A.A.S. Teoria crítica, filosofia e educação: homenagem a Pedro L. Goergen. Passo Fundo, RS; Maringá, PR: Editora UPF; Editora UEM, 2014.

PICHÉ, C. A passagem do conceito epistêmico ao conceito pragmatista de verdade em Habermas. In: LEITE, L. B.; BARBOSA, R. J. C. (orgs.). Filosofia prática e modernidade. Rio de Janeiro: Eduerj, 2003. p. 7-26. 